\title{
A RECONFIGURABLE SINGLE-TO-DUALBAND BANDPASS FILTER FOR WIRELESS APPLICATIONS
}

\author{
Tulika Sinha \\ Junior Engineer, Department of PCM, \\ Bharat Sanchar Nigam Limited, Ahmednagar, Maharashtra, India
}

\begin{abstract}
In this paper a filter is designed using open stub loaded stepped impedance resonators on Taconic RF35 substrate. This filter is reconfigured to switch from a single band-to-dualband bandpass filter using switches in the range 1.87-2.08G $\mathrm{Hz}$ and 2.024-2.206GHz for single bands and 1.95- 2.11GHz and 2.22-2.35G $\mathrm{Gz}$ for dualband bandpass filter. Thus different bands are available for various wireless applications.
\end{abstract}

Keywords: Stub Loaded Stepped Impedance Resonators, Close Band, Bandpass Filter, Reconfigurable Filter.

Cite this Article: Tulika Sinha, A Reconfigurable Single-to-Dualband Bandpass Filter for Wireless Applications, International Journal of Electronics and Communication Engineering and Technology, 10(3), 2019, pp. 14-18.

http://www.iaeme.com/IJECET/issues.asp?JType=IJECET\&VType=10\&IType=3

\section{INTRODUCTION}

Reconfigurable filters increase the functional ability of the microwave filters. They allow the user to enjoy the various services of the wireless communications occurring at different frequency bands. Reconfigurable filters change the properties of the filter by changing the current or the field pattern by the use of switches. The various switches that can be used for reconfiguration are the pin diodes, varactor diodes, ferroelectric diodes, RF microelectromechanical systems (RF MEMS) devices. Thus, the nonlinear behaviour of reconfigurable filter mainly depends on these tuning elements [1]. A close ring resonator based on stepped impedance resonators is designed [2] to generate single band. The stub centrally loaded [3] splits the poles into four to create a dualband bandpass filter.

In this paper a single-to-dual band bandpass reconfigurable filter is designed using open stub loaded centrally to the closed ring stepped impedance resonators. This allows to switch a bandpass from single band to dual band and vice versa. Thus, the user can use different bands as per the need for the required wireless services. 


\section{FILTER THEORY}

\subsection{Stub Loaded Stepped Impedance Resonators}

A stub loaded centrally to stepped impedance resonators is as shown in Fig.1.

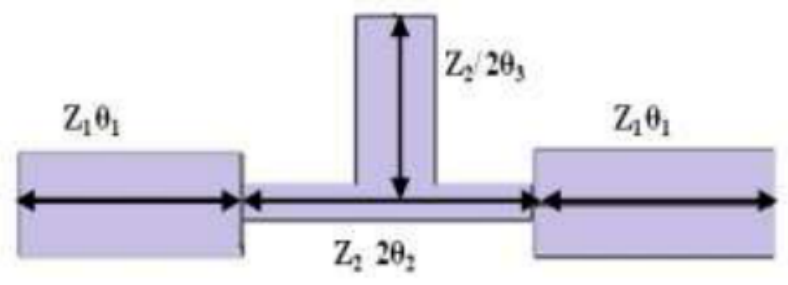

Figure 1 Layout of stub loaded SIR

The stub loaded centrally causes the poles to split into two. Here the $Z_{i}$ denotes the impedances of the stubs, $\theta_{\mathrm{i}}$ signifies the electrical length. From [4] and [5], at resonance the stubs electrical length is $\lambda_{g} / 2$ satisfying the equations as shown below:

$$
\tan \left(\theta_{1}\right) \tan \left(\theta_{2}\right)=Z_{2} / Z_{1}
$$

\subsection{Reconfigurable Filters}

Reconfigurable filters are the microwave filters that change the field or current patterns flowing in the resonators of the filter. The changes are made using switches, i.e., pin diodes; that allows the path for transmission when $\mathrm{ON}$ and ceases transmission when it is OFF.

\section{FILTER DESIGN}

The two centrally loaded open stub stepped impedance resonators (OSL-SIR) are designed on Ansys HFSS simulation tool using substrate Taconic RF-35 with relative permittivity $\varepsilon_{\mathrm{r}}=3.5$ and thickness $t=0.508 \mathrm{~mm}$ as shown in the Fig.2. The lengths of the stub are denoted as $\mathrm{L}_{\mathrm{i}}$, widths as $\mathrm{W}_{\mathrm{i}}$ with transmission line of impedance $50 \Omega$. The various dimensions of the simulated filter are tabulated in TABLE I:

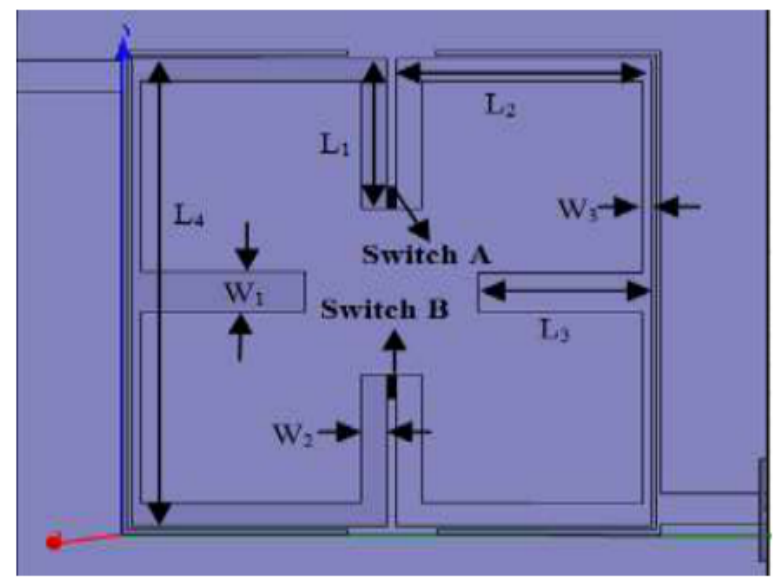

Figure 2 Layout of the reconfigurable bandpass filter 
Table 1 various Dimensions of the Filter

\begin{tabular}{|c|c|}
\hline Dimensions & Values(mm) \\
\hline L1 & 5.0 \\
\hline L2 & 7.9 \\
\hline L3 & 5.5 \\
\hline L4 & 16.5 \\
\hline W1 & 1.40 \\
\hline W2 & 0.80 \\
\hline W3 & 0.28 \\
\hline
\end{tabular}

To this designed bandpass filter, two pin diodes are attached at the two positions as shown in Fig. 2. Here two diodes are used therefore total of four states of switches are defined as discussed further. First case when both the switches are in OFF state, then the OSL-SIRs resonate generating single band of $350 \mathrm{MHz}(1.82-2.17 \mathrm{GHz})$ bandwidth with two poles at $1.87 \mathrm{GHz}$ and $2.08 \mathrm{GHz}$.

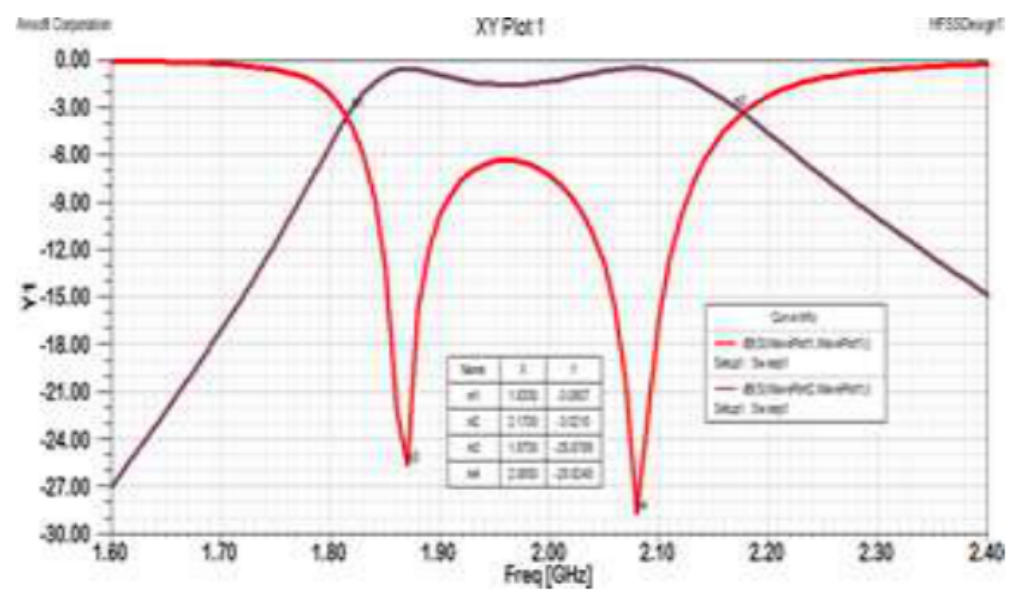

Figure 3. $\mathrm{S}_{11} \& \mathrm{~S}_{21}$ for switch $\mathrm{A}=\mathrm{B}=\mathrm{OFF}$

In the second case when switch $\mathrm{A}$ is $\mathrm{ON}$ and $\mathrm{B}$ is OFF, a single band of $190 \mathrm{MHz}$ in the range $2.02-2.21 \mathrm{GHz}$ is achieved having center frequency at $2.11 \mathrm{GHz}$.

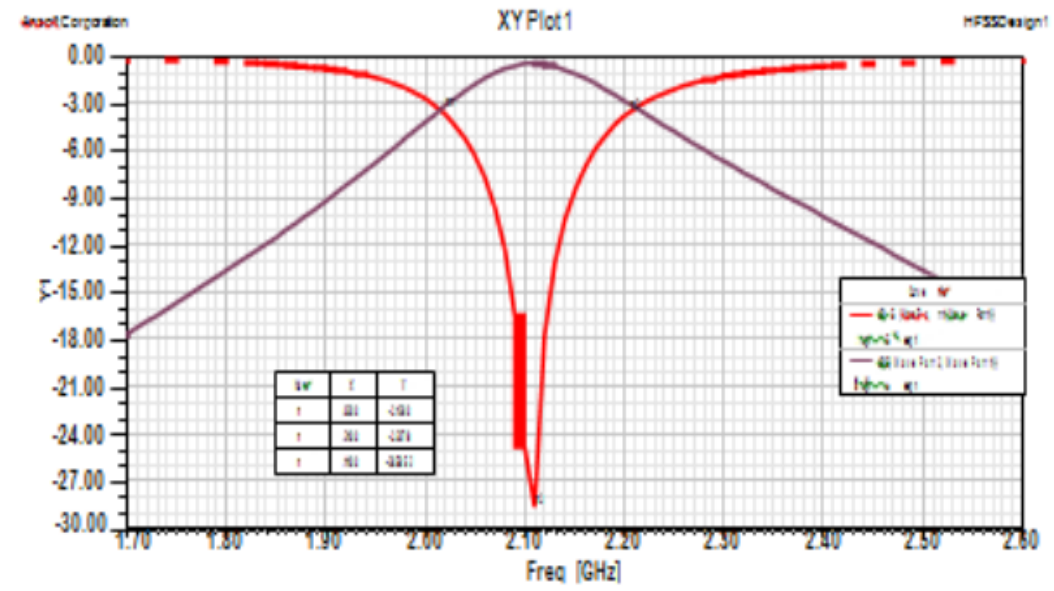

Figure $4 \mathrm{~S}_{11} \& \mathrm{~S}_{21}$ for switch $\mathrm{A}=\mathrm{ON}$ and $\mathrm{B}=\mathrm{OFF}$ 
In the third case, when switch $\mathrm{A}$ is $\mathrm{OFF}$ and switch $\mathrm{B}$ is $\mathrm{ON}$ a band is obtained with $182 \mathrm{MHz}$ bandwidth in the range $2.024-2.206 \mathrm{GHz}$ center frequency located at $2.106 \mathrm{GHz}$. So, case third is better as compared to second with respect to return loss comparison.

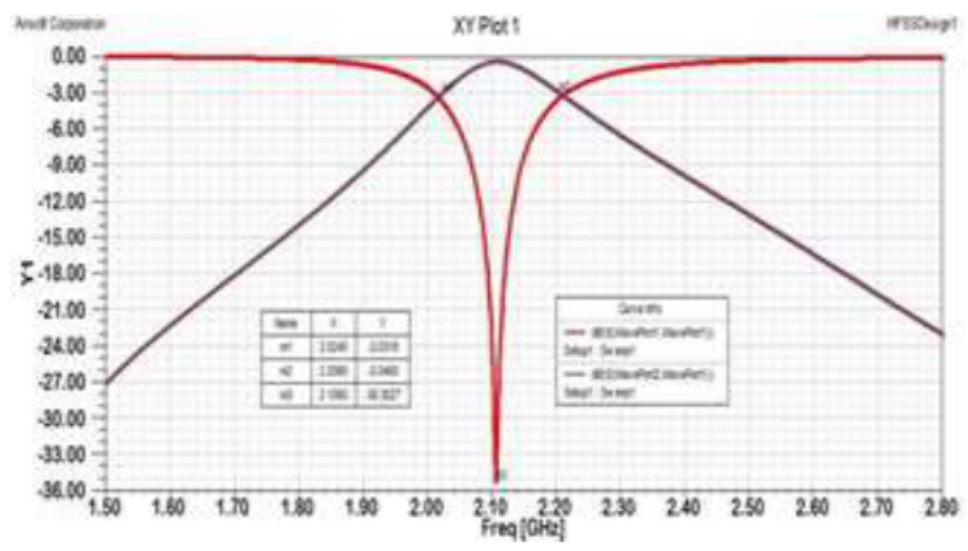

Figure 5. $\mathrm{S}_{11} \& \mathrm{~S}_{21}$ for switch $\mathrm{A}=\mathrm{OFF}$ and $\mathrm{B}=\mathrm{ON}$

When both switches are in ON state, then dual bands are obtained in the range 1.95$2.11 \mathrm{GHz}$ and $2.22-2.35 \mathrm{GHz}$ with center frequencies at $2.06 \mathrm{GHz} \& 2.26 \mathrm{GHz}$. Thus allows two bands that reduces chances of interference of the signals.

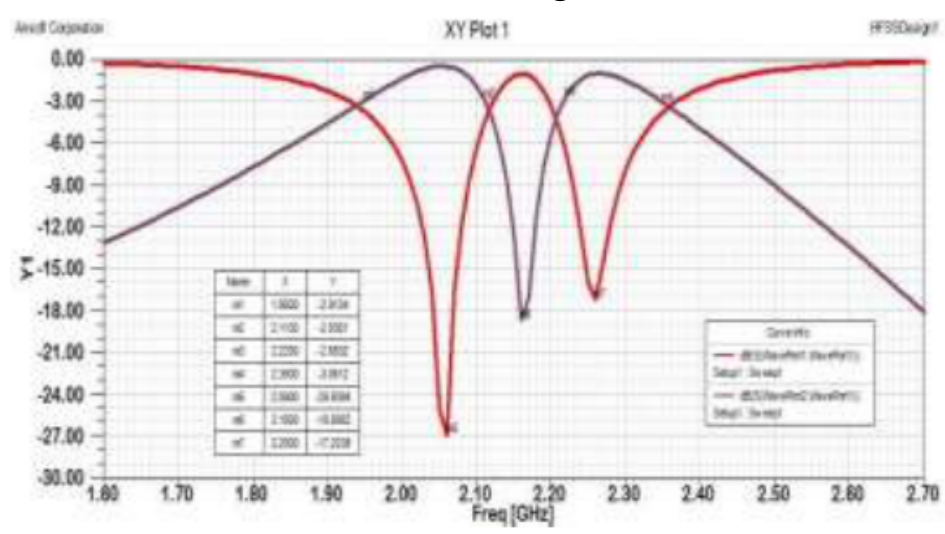

Figure 6. $S_{11} \& S_{21}$ for switch $A=B=O N$

\section{CONCLUSIONS}

In this paper a compact reconfigurable single-to-dual band bandpass filter is designed using open stub loaded centrally to stepped impedance resonators [6]. It operates in bands 1.87$2.08 \mathrm{GHz}$ and $2.02-2.21 \mathrm{GHz}$ with fractional bandwidth of and 9 respectively for single band bandpass filter. Similarly, for reconfigured dualband bandpass filter the bands lie in the range $1.95-2.11 \mathrm{GHz}$ and $2.024-2.206 \mathrm{GHz}$ with fractional bandwidths of 7.9 and 5.7. Thus, a filter can be switched to single or dual band bandpass filter using switches. This enables to use different bands as per the necessity and loads of the users to be benefitted by the various wireless services therefore reducing chances of interference between the signals [6]-[7]. 


\section{REFERENCES}

[1] J. S. Hong and M. J. Lancaster, Microstrip Filters for RF/Microwave Applications, 2001, New York: Wiley, pp.563.

[2] Y.-M. Chen, S.-F. Chang, C. Y. Chou, and K.-H. Liu, "A Reconfigurable Bandpass-to-Bandstop filter Based on Varactor-Loaded Closed Ring Resonators," IEEE Microw. Mag, Volume 10, Number 1, pp. 138-140, Feb.2009.

[3] Daotong Li, Yonghong Zhang, Kaijun Song, Kaida Xu \& Joshua L.-W. Li, "Miniaturized Close Dual-Band Bandpass Filter Based on Short Stub-Loaded Stepped-Impedance Resonators," in Electromagnetics, Volume 35, pp. 49-58, February 2015.

[4] Makimoto, M., \& S. Yamashita, Microwave Resonators and Filters for Wireless Communication. Springer New York. 2001, Chapter 2.

[5] Lei Zhu, Sheng Sun, Rui Li(auth.), Kai Chang(eds.)- Microwave Bandpass Filters for Wideband Communications, 2002

[6] Sinha, T, Pandey, A, K and Chauhan, R.K. A Bandpass-Bandstop Reconfigurable Filter for Wireless Applications. I-Manager's Journal on Embedded Systems, 5(3), 17-20, 2016

[7] T. Sinha, A. K. Pandey and R. K. Chauhan, "A Compact Dualband Bandpass-ToBandstop Tunable Filter For Wireless Applications," 2016 International Conference on Emerging Trends in Communication Technologies (ETCT), Dehradun, 2016, pp. 1-4. 